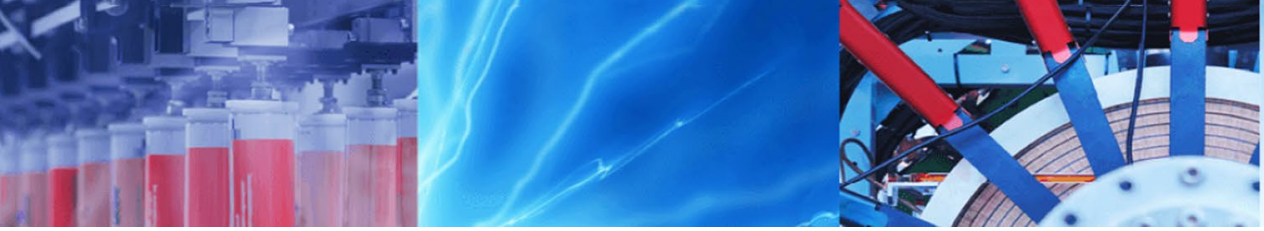

Research Article

\title{
Analyzing the impacts of urbanization on runoff characteristics in Adama city, Ethiopia
}

\author{
Dejene Tesema Bulti ${ }^{1}$ [D $\cdot$ Birhanu Girma Abebe ${ }^{1}$
}

Received: 26 December 2019 / Accepted: 27 May 2020 / Published online: 1 June 2020

(c) Springer Nature Switzerland AG 2020

\begin{abstract}
Urbanization is a global trend with a substantial environmental impacts, particularly hydrologic cycle. With this respect, storm water management has become the main target of sustainable urban development and has posed the higher demand for information related to the interaction between the urbanization process and hydrological attributes in both temporal and spatial scales, but little is understood in the context of Ethiopian urban centers. For this, the fast grown and flood vulnerable urban area, Adama city, is considered to evaluate the hydrologic influences attributable to urbanization. By preparing the land use/land cover (LULC) maps of the study area for different periods, the dynamics of LULC transformations were analyzed. The SCS-CN method was employed to determine the runoff at respective years, and the spatio-temporal changes of runoff were assessed at the city watershed and its sub-watersheds. The relation between the spatio-temporal changes of imperviousness ratio and runoff depth was explored through regression analysis. The findings show that the urban built-up area undergone about 22\% expansion annually from 1995 to 2019. Likewise, the runoff depth is increased by $9.5 \%$ in the City administration and $12.9 \%$ and $6.9 \%$ within the two sub-watersheds. The results also reveal that at all spatial scales, the temporal change of runoff depth is linearly associated with the rise of imperviousness ratio. This study would help planners in the formulation of effective land use plan to manage the hydrological influences of urbanization, thereby supports the efforts being made to ensure the sustainable development of urban areas.
\end{abstract}

Keywords Urbanization · Urban flood · Land cover dynamics · Runoff · Sustainability · Urban development

\author{
Abbreviations \\ LULC Land use/land cover \\ PIA Percent Impervious area \\ SCS-CN Soil conservation service curve number
}

\section{Background}

Around the world, more people are concentrated in towns and cities. In 2017, the proportion of urban population was 55 percent, it is estimated to reach 68 percent in 2050 [54]. Urbanization is undeniably an ongoing global trend with substantial alterations of land use/land cover (LULC) [16,
42]. LULC changes are the main causes of global environmental change $[20,23,29,30]$, and manifest in climatological, biodiversity and hydrological responses.

Urbanization significantly contributes to the occurrence of pluvial floods [18, 19,44]. By modifying land cover around many urban areas, it increases impervious surfaces that reduces infiltration and resistance to flow [10, 34]. Consequently, the volume and flow rate of the runoff rise, thereby exceeding the acceptance of local drainage capacity. Urban floods are the major threats to several cities world wide, and its frequency and related risks are likely to increase in the future $[42,43]$. In the context of developing countries, unplanned urban growth is the common

Dejene Tesema Bulti, dejenetesema@yahoo.com; Birhanu Girma Abebe, birhanu.girma@eiabc.edu.et | ${ }^{1}$ Department of Urban and Regional Planning, Ethiopian Institute of Architecture, Building Construction, and City Development, Addis Ababa University, Addis Ababa, Ethiopia. 
scenario [2], leading to rapid densification, and the construction of buildings is associated with a rapid increase of impervious land areas.

It has long been recognized that the increase in impervious surface increases the surface runoff, but few recent studies $[45,50,59]$ have highlighted the deviations from direct relationship, suggesting the impacts have regional limitations, mainly depend on the spatial distribution of impervious surfaces within a watershed and the scale of the study area. In addition, other LULC changes could also counterbalance the effects of increased impervious area [11]. Hence, understanding the relationship between the trends of the temporal dynamics of impervious ratio and runoff characteristics of watershed and sub-watersheds can be useful information for formulation of effective planning to control the hydrological effects of urbanization, thereby supports the efforts being made to ensure sustainable development of urban areas.

In the context of Ethiopia, studies [15, 17, 25, 26, 35, $48,57]$ have been conducted to assess the effects of LULC change on watershed hydrology; however, they focused on a riverine basin. Among a few studies focusing on urban watershed, Billi et al. [4] compared the relative role of land use change and rainfall intensity in augmenting the frequency of flash flood in Dire Dewa town, due to Dechatu River from 1985 to 2006. By taking Addis Ababa City, as a case, Birhanu et al. [5] analyzed the flood risk and vulnerability attributable to urbanization and climate change for the period of 1993-2002 using Soil and Water Assessment Tool. However, the issue of spatial variability of the impact of impervious area due to urbanization in different sub-catchments is not well addressed. Focuses on the impacts of urbanization on flood are extending progressively from hydraulic channels, to impervious ratio and impervious pattern in urban settings [50]. Neighborhood has become the dominant design unit in the contemporary urban planning for storm water management in urban areas, less likely using the catchment $[36,50,55]$.

Since the turn of this century, Adama city has been recognized as one of the rapidly grown and flood vulnerable urban areas in the country $[6,8]$, yet adequate understanding of the influences of urbanization on hydrological characteristics of the city is lacking. Sinha et al. [49] examined the built-up area expansion of Adama municipal area from 1984 to 2015 , but the related environmental impacts, particularly on the hydrology are not addressed. In response to the existing flooding problems of Adama city, and the thoughtfulness of a potential increase in the future, proper storm water management demands spatio-temporal information related to interaction between urbanization process and hydrological characteristics of the city.

The central aim of this study is to analyze the spatiotemporal changes of the storm runoff depth in Adama city under the influences of urbanization from 1995 to 2019. More specifically, it is conducted (1) to analyze the spatio-temporal changes of LULC in Adama city administration from 1995 to 2019; (2) to determine the variations of runoff depth due to the LULC changes and (3) to explore the relationship between the spatio-temporal changes of imperviousness due to urbanization and the runoff depth.

\section{Materials and methods}

\subsection{The study area}

Adama city is one of the fast-growing and flood vulnerable urban areas in Ethiopia [8]. It is located at $8^{\circ} 33^{\prime} \mathrm{N}$ latitude and longitude $39^{\circ} 16^{\prime} \mathrm{E}$ longitude. The city is suited in Rift Valley, on flat terrain characteristics and surrounded by mountains and ridged topography. The latest approved land use plan of the city is prepared in 2004 [7]. The administrative boundary set by this plan is selected to limit the spatial extent of the analysis. The city falls in two, main watersheds: Awash and Mermersa (Fig. 1), with spatial coverage of 7, 329.7 ha and 6, 036.8 ha, respectively.

The growth rate of population of Adama city from 2004 to 2016 is about 9\% [6]. Since August 2000, Adama has become the seat of the National Regional State and Capital city of Oromia, the largest Regional State in the country. This Administrative status, largely considered as the main driver for the rapid urbanization of the city. Hence, timeseries analysis of LULC in the city administration from 1995 to 2019 is deemed appropriate to provide enhanced picture of the impacts of urbanization on hydrological characteristics of the area.

\subsection{Data used and image pre-processing}

\subsubsection{Spatial data}

The spatial data used in this study were collected from different sources, including websites, organizations. Landsat 7 TM/ETM + (Enhanced Thematic Mapper Plus) (L1TP product of path 168 , row 54 ) was used for mapping LULC of the study area. Landsat image is widely used for urban LULC mapping, despite its medium spatial resolution and mixed pixel problem [12]. It is freely accessible for multiple dates and considered suitable for time-series analysis. One image from each year with free cloud contamination, except that of 2015 (Table 1) was accessed from the United States Geological Survey (USGS) (https://espa.cr.usgs. gov/). All bands of the landsat image have $30 \mathrm{~m}$ spatial resolution. Landsat Level 1 (L1T) images are geometrically corrected and orthorectified by the National Aeronautics and Space Administration (NASA) [28]. 


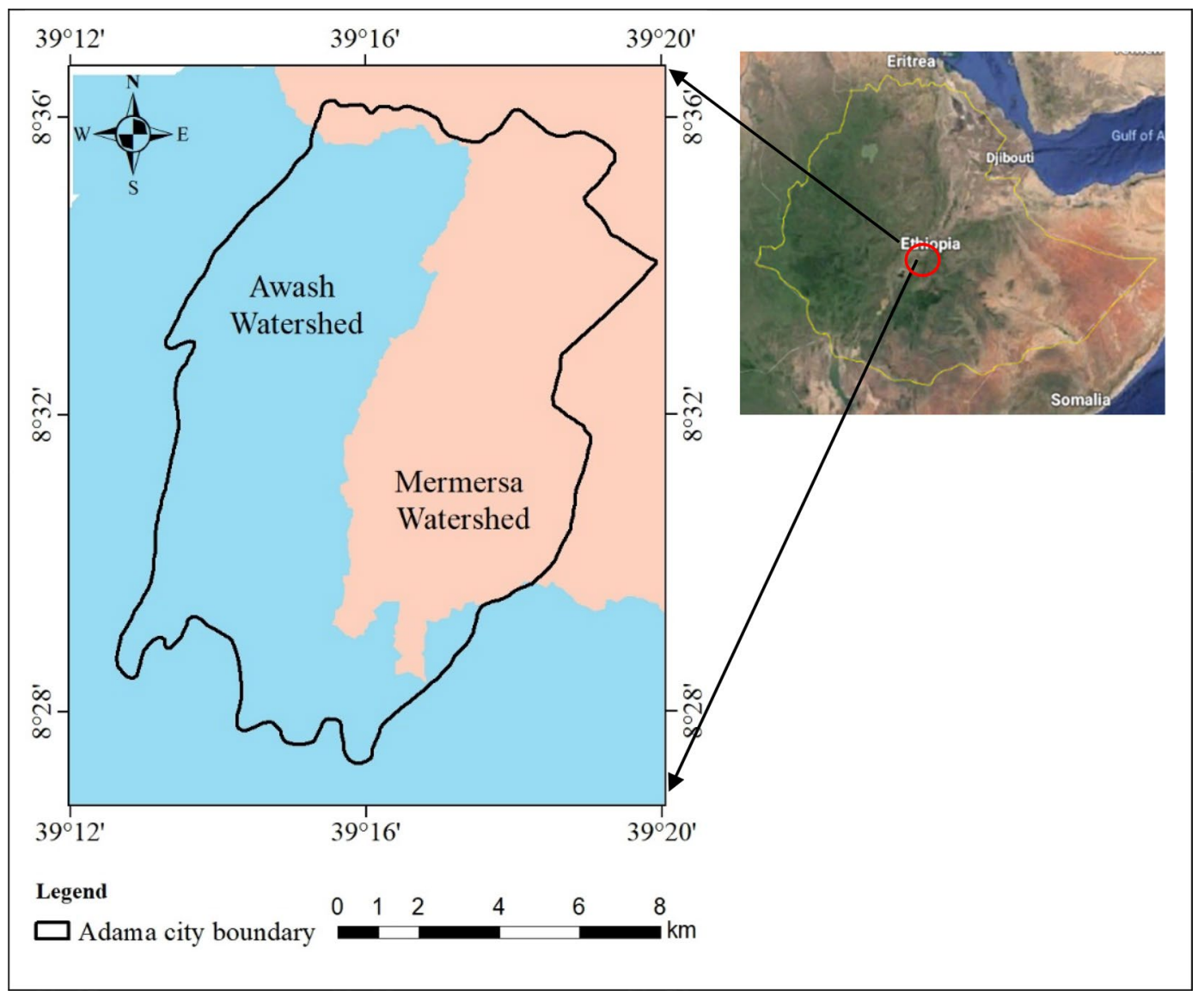

Fig. 1 Location map of the study area

Table 1 Date of acquisition and the cloud cover (\%) of landsat images used for LULC mapping

\begin{tabular}{lllllll}
\hline Year & 1995 & 2000 & 2005 & 2010 & 2015 & 2019 \\
\hline Date of acquisition & Jan 30, 1995 & Feb 05, 2000 & Feb 18, 2005 & Jan 15, 2010 & Feb 14, 2015 & Jan 08, 2019 \\
Cloud cover & - & - & - & - & $1 \%$ & - \\
\hline
\end{tabular}

In this study, the LULC maps serve as the base of the analysis, the accuracy of LULC classification has direct significant impact the reliability of the runoff depth analysis. Accordingly, all images are selected among acquired during the dry season, as the accuracy of landsat image classification during the dry season is found to be higher than during the wet season [32]. Further, the atmospheric effects were reduced through conversion of raw digital number (DN) values to the surface reflectance in radiometric calibration module in ENVI software.

Soil map of the study area was collected from institute of water resource engineering, Adama Science and Technology University. Digital orthophoto acquired in 2014 and 2018 with $15 \mathrm{~cm}$ spatial resolution were obtained from Adama city administration.

\subsubsection{Rainfall data}

The daily rainfall data for a period of 30 years (1985-2014) recorded at Adama meteorological station was collected from the National Meteorological Agency (NMA) of Ethiopia, Adama branch office. The data were checked for missing values, and few gaps ( 91 days about $0.9 \%$ ) identified in the data were filled using XLSAT. Daily precipitation values were aggregated to give annual rainfall (Fig. 2). Accordingly, the maximum, minimum, and mean annual precipitation over the last 29 years (1985-2014) are $1371 \mathrm{~mm}$, $629 \mathrm{~mm}$, and $920 \mathrm{~mm}$, respectively.

In Adama, most of the rain occurs from June to September, whereas the wettest months are July and August. The maximum daily precipitation in rainy season 


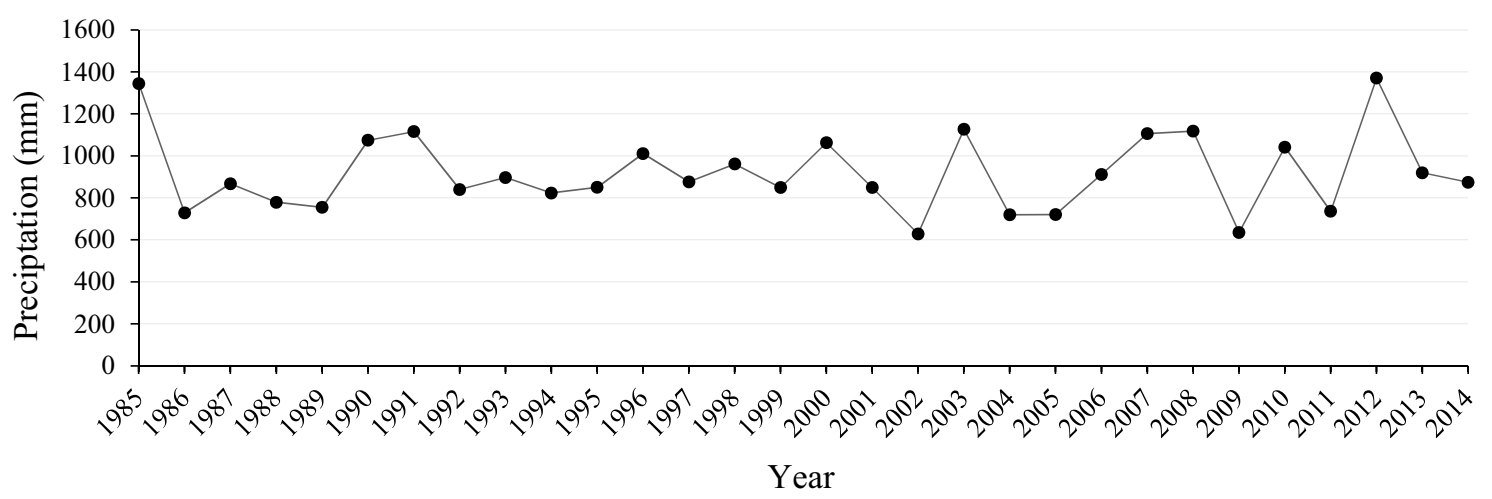

Fig. 2 Annual rainfall of Adama city from 1985 to 2019

(June-September) was selected for runoff computation for analyzing the impacts of urbanization on runoff response in the city administration, and its sub-catchments. It is found to be $99.8 \mathrm{~mm}$, precipitation record corresponding to July 18,2000 . It is used for the study, and helped to distill the impacts of LULC on the surface runoff depth of the study area, by reducing the effect of rainfall variations.

\subsection{Land use/land cover mapping}

Considering the importance of short-term changes in urban areas due to rapid urbanization and climate changes [59], LULC maps of the study area were prepared at about 5 years' interval (1995, 2000, 2005, 2010, 2015 and 2019) using landsat images through supervised classification method. It involves defining classification scheme, selection of training samples, running an algorithm to assign each pixel into a class and accuracy assessment.

\subsubsection{Defining classification scheme}

The analysis focused on spectral resolution because the spectral dimension is the most important source of cover type information in coarse resolution images. The success of LULC usually measured by the ability to match the spectral classes in the data to the information classes of interest [56]. Spectral classes refer to the groups of pixels with similar (or near-similar) brightness values in the diverse spectral bands of the data. Whereas, information classes are those classes of concern that the analyst is attempting to identify within the imagery.

In a complex urban landscape, a particular land use class may have diverse spectral characteristics (e.g., Roof cover of old and new buildings). By contrast, different classes (objects) can have the same spectral characteristics (e.g., Rock and concrete or bright building roofs). Hence, a simple one-to-one relation between the two types of classes is rarely identified. Many times it is found that 2-3 spectral classes merge to form one informational class.

Given the importance of the appropriate classification scheme, in this study, initially, by visually analyzing the color composite landsat images with different band combinations, different classes were identified, and aggregated into four: urban, bare land, agriculture and vegetation (Table 2).

\subsubsection{Training sample selection}

Training samples for each class were collected from each image. In order to reduce the sampling biases, consistency in sample selection was kept by selecting pixels that remained unchanged at different times to train the classifier. First, samples were selected from landsat image of 1995 (first image). Subsequently, these samples were

Table 2 Land use/land cover classification scheme used in the study

\begin{tabular}{ll}
\hline LULC class & Description \\
\hline Urban & $\begin{array}{c}\text { Comprises areas with all types of artificial surfaces, including buildings and transportation infrastruc- } \\
\text { ture (asphalt, gravel, railway). Areas under construction are also included } \\
\text { Includes a surface with no or little vegetation, open land, exposed soil, rocks and sand (eroded gullies) }\end{array}$ \\
$\begin{array}{l}\text { Barren land } \\
\text { Agricultural }\end{array}$ & $\begin{array}{l}\text { Comprises areas with vegetation cover, such as areas covered with both indigenous and exotic tree } \\
\text { and shrub land. It also includes green spaces in built-up areas: an area of grass, trees, or other veg- } \\
\text { Vegetation }\end{array}$ \\
& etation set apart for recreational or aesthetic purposes inside urban built environment \\
\hline
\end{tabular}


treated as training samples for the first image and used as a base for the adjacent image (2000). Second, the base samples were overlaid with the second image to check if change in class occurred. If changes were observed, new sample with more confidence was substituted from the surrounding area. Similarly, the same procedures were followed by selection of training samples for the rest of the images.

As a general rule, the number of sample pixels for each subclass was determined based on the recommendation of Sertel and Akay [47], which sate that the number of pixels of training samples for each class should be at least 10 times the number of bands in an image to classify. In this study, the total number of training pixels used for each LULC class alongside the respective years is summarized in Table 3.

\subsubsection{Classification algorithm}

Each image was classified into a set of spectral classes using Support Vector Machine (SVM) algorithm in ENVI software. SVM is non-parametric classifier. Unlike parametric classifiers such as maximum likelihood which assumes that the data is normally distributed, non-parametric classifiers do not base classification on a normality assumption or statistical parameters [39]. Because of highly heterogeneous land covers data (e.g., Urban areas) are unlikely normally distributed, the distribution of land cover surfaces is associated with various uncertainties which prevents their description based on data distribution [33]. In this respect, non-parametric classifiers provide better results as compared to parametric classifiers in complex landscapes.

\subsubsection{Accuracy assessment}

Accuracy of land use maps is important in urban studies [47]. In thematic mapping from remote sensing data, classification accuracy refers to the level to which the resulting image classification conforms to the 'truth' or agrees with the reality [22]. This is usually undertaken by using information collected from the map and the reference sources. Reference sample data is the class label, which derived from sources that are assumed to be correct. Whereas, map sample data refers to the data derived from the map being assessed. A reference sample data for assessing the accuracy of maps created from moderate-resolution satellite imagery (e.g., Landsat) can be collected from a variety of sources, including previously existing maps, aerial photography and Google Earth $[1,14,21,53]$.

In this study, LULC classification accuracy was assessed quantitatively using error matrix which is the commonly used method in LULC classification accuracy assessment [56]. In this regard, sample pixels were selected from each of classified images through a stratified random sampling scheme in ENVI software. This enables to undertake unbiased sample selection, as it includes each LULC class in the sample [14].

The samples were overlaid with the existing map (for 1995), Google Earth (for 2000, 2005 and 2010) and digital orthophoto (for 2015 and 2019) to visually interpret and determine their respective classes. Based on the error matrix generated for each classified map, overall accuracy, user's accuracy and producer's accuracy were calculated, in addition to kappa variance. The accuracy requirements for change detection analysis were determined based on the suggestion of Congalton and Green [14]. In this case, the value of the Kappa statistics, greater than 0.8 , indicates strong agreement between the class label on the map and on the reference data.

\subsection{Methods}

\subsubsection{Analysis of LULC dynamics}

The spatio-temporal changes of LULC were identified using areal data generated from LULC maps in GIS environment. Quantitative areal data from the overall LULC changes, as well as gains and losses in each class were compiled to analyze the nature and rate of the changes. The percentages of changes were computed using Eq. 1. In this case, the positive and negative values suggest a gain and loss in spatial extent, respectively.

Percentage change LULC $\left(\Delta_{\text {LULC }}\right)$

$$
\Delta_{\text {LULC }}=\frac{A_{2}-A_{1}}{A_{1}} * 100
$$

Table 3 Summary of the number of traiaing samples

\begin{tabular}{lrrrrrr}
\hline LULC class & \multicolumn{7}{l}{ Year } & & & & \\
\cline { 2 - 6 } & 1995 & 2000 & 2005 & 2010 & 2015 & 2019 \\
\hline Agriculture & 1709 & 1430 & 1764 & 1183 & 1269 & 807 \\
Barren & 1640 & 1276 & 1493 & 1685 & 1761 & 1890 \\
Urban & 650 & 698 & 883 & 1071 & 1556 & 1995 \\
Vegetation & 610 & 606 & 801 & 524 & 1378 & 1378 \\
\hline
\end{tabular}


where $A_{1}$ and $A_{2}$ are areas of a LULC class in the consecutive years.

\subsubsection{Analysis of imperviousness change}

Imperviousness refers to the areal proportion of impervious surfaces within the defined boundary (e.g., watershed, administrative boundary), i.e., percent impervious area (PIA). Impervious surface in urban areas, generally comprises anthropogenic features (e.g., Buildings, parking lots, roads, etc.) which rainfall water cannot permeate, and they are usually associated with urban expansion [52, 59]. These features are categorized under urban land use class in this study and considered as impervious surfaces, similar to other studies [31, 38, 40,58]. In this regard, the urban class in each watershed was extracted and the area was computed to provide the extent of impervious surface in respective watersheds.

PIA was calculated by using the ratio of impervious surface area at different years to the area of the respective analysis boundaries. The changes of imperviousness were computed with respect to the first year of the analysis (Eq. 2). This helped to assess the impact of urbanization in increasing the impervious surface in the study area.

$\Delta P I A_{i}=\frac{P I A_{i}-P I A_{1995}}{P I A_{1995}} * 100$

where $\triangle P I A_{i}$ : percentage change of imperviousness; $P I A_{i}$ : imperviousness in respective years; $P I A_{1995}$ : imperviousness in the baseline year (1995).

\subsubsection{Evaluation of spatio-temporal changes of runoff depth}

Evaluation of the temporal variations of the runoff depth due to the impacts of LULC changes involves computation of runoff and percentage change with respect to a baseline/reference year. Rainfall-runoff was estimated using the method of soil conservation service curve number (SCS$\mathrm{CN}$ ). It is simple and stable conceptual technique for direct runoff depth estimation based on rainfall depth [51]. SCS$\mathrm{CN}$ is well-established method, having been commonly used for examining the relationship between different land uses and runoff in water resources management and planning $[13,27,41,59]$. SCS-CN method provides an adequate result with a minimum information that makes it more useful for ungauged watershed [10,37]. The value of $\mathrm{CN}$ reflects the impact of land cover on the runoff yield ranging from 0 (100\% infiltration) to 100 (0\% infiltration). Evapotranspiration losses are insignificant in the storm event [11].
Runoff can be easily obtained using three important properties of the watershed: soil permeability, land use and antecedent soil water conditions $[3,11]$. Initially, the soil types in the study area were converted to hydrologic soil group (HSG). The CN for each LULC class is determined and found to be $72,91,93$ and 50 for agriculture, bare land, urban and vegetation, respectively.

The analysis is conducted at the city and sub-catchment levels, and the study watersheds encompass different LULC class alongside different spatial extent. To determine a single curve number for respective analysis boundaries for runoff estimation using SCS-CN method, the catchments were spatially intersected with LULC maps and the area of each class in each catchment was computed. Then, the weighted $\mathrm{CN}$ for respective watersheds was computed using Eq. 3.

The 5 days' (July $14-18,2000$ ) rainfall magnitude is found to be $137 \mathrm{~mm}$. Based on Subramanya [51] recommendation, wet antecedent moisture condition was selected. Based on this, Eqs. 4 and 5 were applied for converting the average antecedent moisture condition into wet condition and for computing the potential maximum soil retention, respectively. Using daily rainfall, the accumulated runoff depth in respective areas was computed using Eq. 6.

$C N_{w / l}=\frac{\sum_{i=1}^{n} C N_{i} a_{i}}{\sum_{i=1}^{n} a_{i}}$

$C N_{I I I}=\frac{C V_{w / l}}{0.427+0.00573 C N_{l l}}$

$S=\frac{25,400}{C N_{w}}-254$

$Q=\frac{(P-0.2 S)^{2}}{(P+0.8 S)}$

where Q: accumulated direct runoff depth $(\mathrm{mm}) ; \mathrm{P}$ : accumulated rainfall $(\mathrm{mm})$; $S$ : potential maximum retention (mm).

Using the computed runoff depth for respective years, the temporal variations of the runoff depth due to the impacts of LULC changes were assessed through runoff depth change ratio. By taking the runoff depth of the first year (1995) as a baseline, the percentage changes in runoff for 2000, 2005, 2010, 2015 and 2019 were computed using Eq. 1. This helped to determine the temporal variations in storm runoff depth attributable to the changes in LULC of the study area with respect to that of the baseline year. 
$\Delta Q_{i}=\frac{Q_{i}-Q_{1995}}{Q_{1995}} * 100$

where $\Delta Q_{i}$ Percentage change of runoff depth; $Q_{i}$ is runoff depth in respective years, $Q_{1995}$ is runoff depth in the reference year (1995).

\subsubsection{Regression analysis}

Regression analysis was carried out to explore the relationship between the spatio-temporal changes of PIA and runoff. It is the common method to investigate the relationship between a quantitative outcome and a quantitative explanatory variable [46].

The validity of the model assumptions was determined by examining the structure of the residuals and the data pattern through graphs. Examination of residual plots is a simple and effective method for validation of standard assumptions in regression analysis [9]. In this context, the normality assumption was validated using a normal probability plot of standardized residuals which is a plot of the ordered standardized residuals against the normal scores. Under normality assumptions, this plot should resemble a (nearly) straight line with an intercept of zero and a slope of one, and they are equal to mean and standard deviation of the standardized residuals, respectively. In addition, scatter plots of the standardized residual against PIA and fitted values were used to validate the linearity assumption. Under the standard assumptions, the standardized residuals are uncorrelated with the explanatory variable and with fitted values. The random scatter of points of these plots explains the validity of linearity assumption.

The strength of the linear relationship between the runoff variations and the PIA was determined using the value of Pearson's correlation coefficient ( $r$ ). It is a dimensionless quantity that commonly used to compare the linear relationships between pairs of variables in different units. Accordingly, the non-zero value of the correlation coefficient indicates the variables are correlated. Further, the positive and negative values indicate direct and indirect relationship, respectively. Moreover, like Bulti and Assefa [6] the strength of the correlation was described using the absolute value of correlation coefficient: very weak $(|r|<0.19)$, weak $(|r|<0.39)$, moderate $(|r|<0.59)$, strong $(|r|<0.79)$, very strong $(|r|<1)$.

Statistical significance testing was also conducted to offer an objective measure in the decision about the validity of the generalization, and it was determined using a $p$ value statistic. In this case, the null hypothesis states that there is no significant relationship between the changes in PIA and runoff. In theory, the p-value is a continuous measure of evidence [24], yet in this study, the term "significant" refers to the $95 \%$ confidence level $(p<0.05)$; it is standard in statistical practice in most of the Engineering researches.

\section{Results}

\subsection{Dynamics of land use/land cover}

Figure 3a-f demonstrates the LULC maps of Adama city for 1995, 2000, 2005, 2010, 2015 and 2019. Overall classification accuracies are $89 \%, 91 \%, 93 \%, 91 \%, 92 \%$ and $90 \%$ for the year 1995, 2000, 2005, 2010, 2015 and 2019, respectively. The values of Kappa statistics for classified images are greater than 0.8 , indicating strong agreement between the classified LULC classes and the reference data, hence the maps satisfied accuracy criteria for LULC change detection analysis.

The information summarized in Table 4 shows the spatial extents, percentage changes over time as well as the annual average growth of the four LULC classes (agriculture, barren land, urban and vegetation) in Adama city between 1995 and 2019. Besides Fig. 4 demonstrates the spatio-temporal variations of the proportions of each class occurred over the span of 24 years.

Overall, the results show the extensive LULC changes in Adama city over the study period. Agricultural land was dominant class at the beginning of the study period, but declined with the continuous increase of urban land area. The rate of annual urban expansion greater by far, from the rest land use classes.

The coverage of agricultural land was slightly less than $50 \%$ of the total area at the beginning of the study timeframe. In the following 10 years, it moderately decreased to about $44 \%$ before it dramatically dropped to nearly $10 \%$ in the final year. By contrast, the proportion of urban class was $5 \%$ in 1995 , this figure rose to just over $30 \%$ in 2019 , showing an increase of more than five folds of its initial spatial share. It showed nearly $22 \%$ of average annual expansion across the study period. Temporally, the rate of urban land expansion was comparatively low in the first 15 years between 1995 and 2010 , which showed nearly $8 \%$ increase, then it peaked about $32 \%$ of the total area in the last year.

On the other hand, vegetation class showed a remarkable increase in spatial cover between 2010 and 2015 has also contributed to the increase of its share of the study area from 11 to $18 \%$ in the first and last years of the study period, respectively. With nearly equal proportion, the areal share of the barren land increased during the study timeframe. 


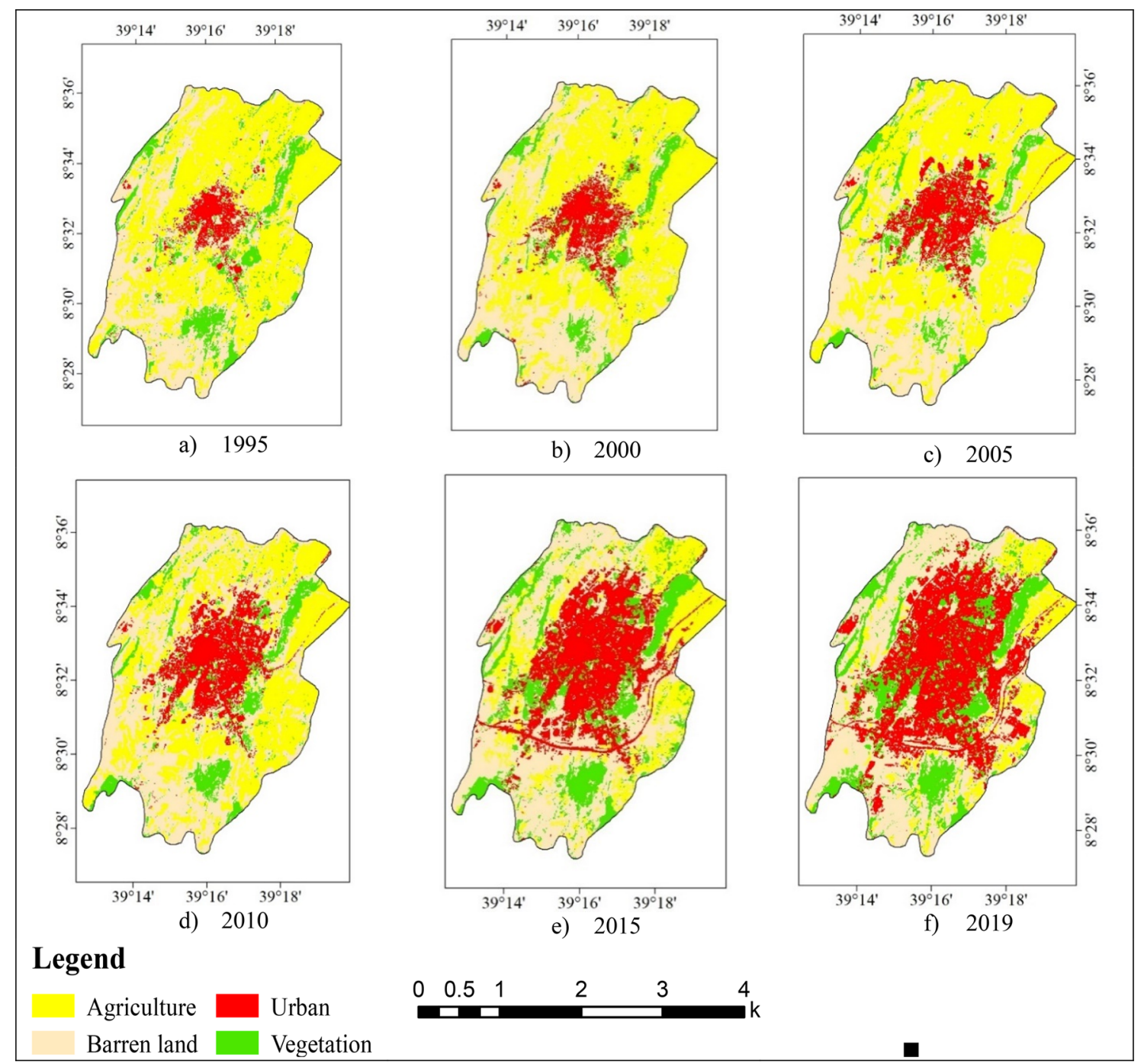

Fig. 3 Land use/land cover maps of the study area from 1995 to 2019

\subsection{Spatio-temporal changes of runoff depth}

The weighted curve number determined for average antecedent moisture condition computed using Eq. 3 is summarized in Table 5. By converting these values to wet moisture condition, the runoff depth of each watershed at different times is computed. The results summarized in Table 6 and depicted in Fig. 5 demonstrate that the daily accumulated runoff depth in the city and its sub-watersheds from 1995 to 2019, with a more detailed look at the trend of change in runoff depth.

Overall, the results indicate the continued increase in runoff depth for the three analysis boundaries during the last 24-year. This rising trend is occurring across all the selected years for the analysis. In all the cases, the accumulated daily runoff depth of the Awash watershed is greater. In addition, during study timeframe, the runoff depth is increased in all areas, except for the Awash watershed that slightly decreased in 2005.

The maximum increased runoff depth is related to Mermersa sub-watershed with $12.9 \%$, whereas the Awash subwatershed showed 6.9\% change. The runoff depth in Awash watershed starts at about $72.9 \mathrm{~mm}$ and steadily increased to $74.8 \mathrm{~mm}$ before it fell to $73.4 \mathrm{~mm}$ in 2005 . Then it goes up to reach $77.9 \mathrm{~mm}$ at the final year. At city scale, the runoff depth starts at slightly less $70 \mathrm{~mm}$ in 1995, this figure is increased to reach over $76 \mathrm{~mm}$ in the final year, indicating about 9.5\% increase in the span of 24-years.

\subsection{Relation between the changes of PIA and runoff depth}

In this study, the degree to which the temporal variations in runoff depth can be explained by the changes of PIA is 

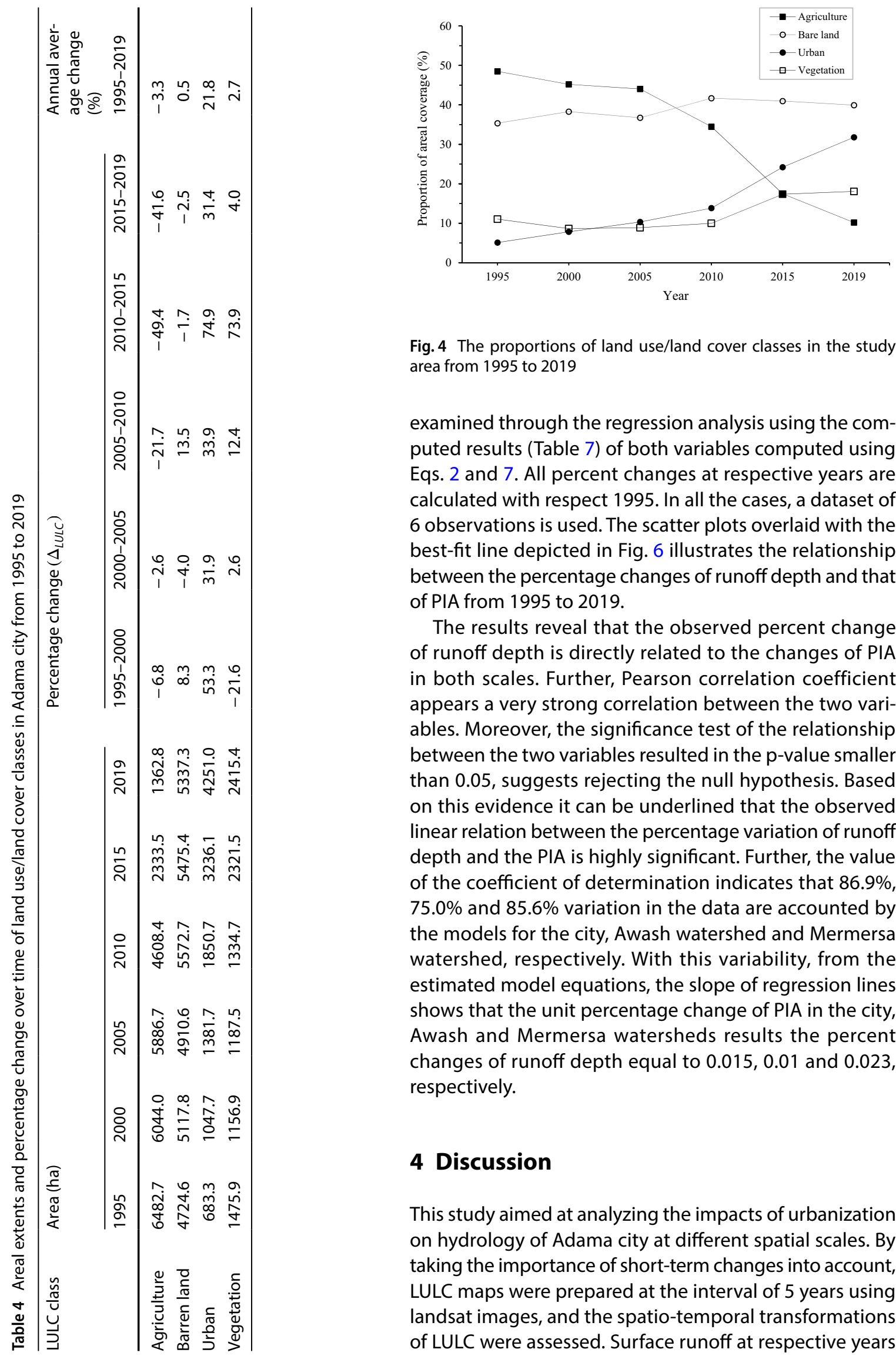

Fig. 4 The proportions of land use/land cover classes in the study area from 1995 to 2019

examined through the regression analysis using the computed results (Table 7) of both variables computed using Eqs. 2 and 7. All percent changes at respective years are calculated with respect 1995 . In all the cases, a dataset of 6 observations is used. The scatter plots overlaid with the best-fit line depicted in Fig. 6 illustrates the relationship between the percentage changes of runoff depth and that of PIA from 1995 to 2019.

The results reveal that the observed percent change of runoff depth is directly related to the changes of PIA in both scales. Further, Pearson correlation coefficient appears a very strong correlation between the two variables. Moreover, the significance test of the relationship between the two variables resulted in the $p$-value smaller than 0.05 , suggests rejecting the null hypothesis. Based on this evidence it can be underlined that the observed linear relation between the percentage variation of runoff depth and the PIA is highly significant. Further, the value of the coefficient of determination indicates that $86.9 \%$, $75.0 \%$ and $85.6 \%$ variation in the data are accounted by the models for the city, Awash watershed and Mermersa watershed, respectively. With this variability, from the estimated model equations, the slope of regression lines shows that the unit percentage change of PIA in the city, Awash and Mermersa watersheds results the percent changes of runoff depth equal to $0.015,0.01$ and 0.023 , respectively.

\section{Discussion}

This study aimed at analyzing the impacts of urbanization on hydrology of Adama city at different spatial scales. By taking the importance of short-term changes into account, LULC maps were prepared at the interval of 5 years using landsat images, and the spatio-temporal transformations of LULC were assessed. Surface runoff at respective years 
Table 5 Summary of the result of weighted curve number for average antecedent condition

Table 6 Daily accumulated runoff depth in the city and its watersheds from 1995 to 2019 (units are in millimeter)

\begin{tabular}{lllllll}
\hline Spatial boundary & 1995 & 2000 & 2005 & 2010 & 2015 & 2019 \\
\hline Awash watershed & 79.7 & 81.1 & 80.1 & 82.5 & 82.5 & 83.4 \\
City boundary & 77.4 & 79.0 & 79.2 & 80.6 & 81.0 & 82.3 \\
Mermersa watershed & 74.6 & 76.5 & 78.1 & 78.3 & 79.3 & 80.9 \\
\hline
\end{tabular}

\begin{tabular}{llllllll}
\hline Spatial boundary & 1995 & 2000 & 2005 & 2010 & 2015 & 2019 & Change of
\end{tabular}
runoff depth (1995-2019)

\begin{tabular}{|c|c|c|c|c|c|c|c|c|}
\hline & & & & & & & (1995 - r & J19) \\
\hline & & & & & & & $\mathrm{mm}$ & $\%$ \\
\hline Awash watershed & 72.9 & 74.8 & 73.4 & 76.7 & 76.6 & 77.9 & 5.0 & 6.9 \\
\hline Mermersa watershed & 66.0 & 68.5 & 70.8 & 71.1 & 72.4 & 74.5 & 8.5 & 12.9 \\
\hline City boundary & 69.8 & 72.0 & 72.2 & 74.2 & 74.7 & 76.4 & 6.6 & 9.5 \\
\hline
\end{tabular}

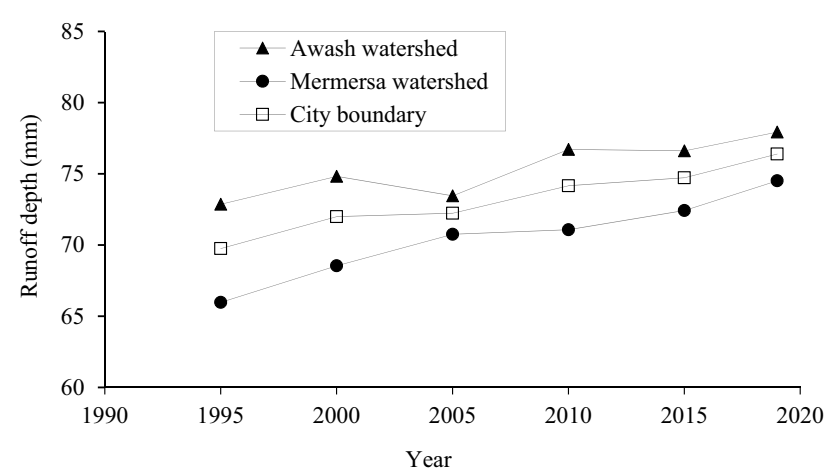

Fig. 5 Daily runoff depth in Adama city and its sub-watersheds from 1995 to 2019

was computed using the SCS-CN method, and the impacts of LULC changes on hydrologic attributes of the city were examined. The relation between urbanization and change in the runoff was explored through regression analysis using the datasets of temporal changes of IAR and runoff depth.

The study reveals extensive LULC changes during the study timeframe, particularly the extent of built-up land has expanded more than five times, indicating averagely the city undergone $22 \%$ urban expansion annually from 1995 to 2019. A built-up expansion rate of $7.9 \%$ during the study period, which is slightly less than the growth rate of the city's population reported by Bulti and Assefa [6]. On the other hand, the result is greater than the findings of Sinha et al. [49]. The disparity could be due to incorporation of transportation (gravel roads and railway) in urban classes in the case of the present study.

The study also indicates that the observed alterations of LULC in the study area resulted in an increase in runoff depth in the city by $9.5 \%$ over the study timeframe. This figure is less than the result of the study [5] reported for the impacts of LULC change in Addis Ababa city over the period of 10 years, and it is greater than that of Billi et al. [4] noted in Dire Dawa town over 21 years. This disparity could be underpinned by local conditions, which can be associated with socioeconomic, level of urbanization, level of spatial planning and environmental variability. At the watershed level, while an increase of $12.9 \%$ in Mermersa, a $6.9 \%$ increase in Awash is found. Along with other (e.g., [11], the findings of this study indicate that the impacts of LULC changes on runoff can be influenced by spatial scale of the analysis. In addition, while urban land continuously increased across the study period, the runoff in Awash watershed decreased from 2000 to 2005. The opposite effect shows that the alterations in other LULC classes appears to counterbalance the impacts of urbanization in storm runoff.

The significant linear relationship between the spatiotemporal variations of runoff and imperviousness ratio is another important finding of this study. The result is slightly different from other studies Sanyal et al. [45] and
Table 7 Percentage change of PIA $\left(\Delta_{\text {PIA }}\right)$ and runoff administration Adama city adminstration and its subwatersheds from 2000 to 2019 with respect to the baseline year (1995)

\begin{tabular}{|c|c|c|c|c|c|c|c|c|c|c|}
\hline \multirow[t]{2}{*}{ Spatial boundary } & \multicolumn{2}{|l|}{2000} & \multicolumn{2}{|l|}{2005} & \multicolumn{2}{|l|}{2010} & \multicolumn{2}{|l|}{2015} & \multicolumn{2}{|l|}{2019} \\
\hline & $\Delta_{\mathrm{PIA}}$ & $\Delta_{\mathrm{Q}}$ & $\Delta_{\mathrm{PIA}}$ & $\Delta_{\mathrm{Q}}$ & $\Delta_{\mathrm{PIA}}$ & $\Delta_{\mathrm{Q}}$ & $\Delta_{\mathrm{PIA}}$ & $\Delta_{\mathrm{Q}}$ & $\Delta_{\mathrm{PIA}}$ & $\Delta_{\mathrm{Q}}$ \\
\hline City boundary & 53.3 & 3.2 & 102.2 & 3.6 & 170.8 & 6.3 & 373.6 & 7.1 & 522.1 & 9.6 \\
\hline Awash watershed & 55.9 & 2.7 & 104.0 & 0.8 & 182.3 & 5.3 & 421.9 & 5.2 & 585.8 & 7.0 \\
\hline Mermersa watershed & 51.5 & 3.9 & 100.9 & 7.2 & 162.4 & 7.7 & 338.1 & 9.8 & 475.3 & 12.9 \\
\hline
\end{tabular}




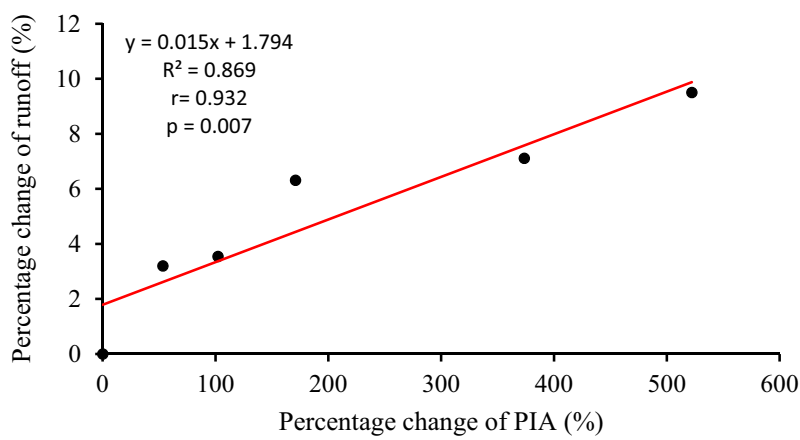

(a) City boundary

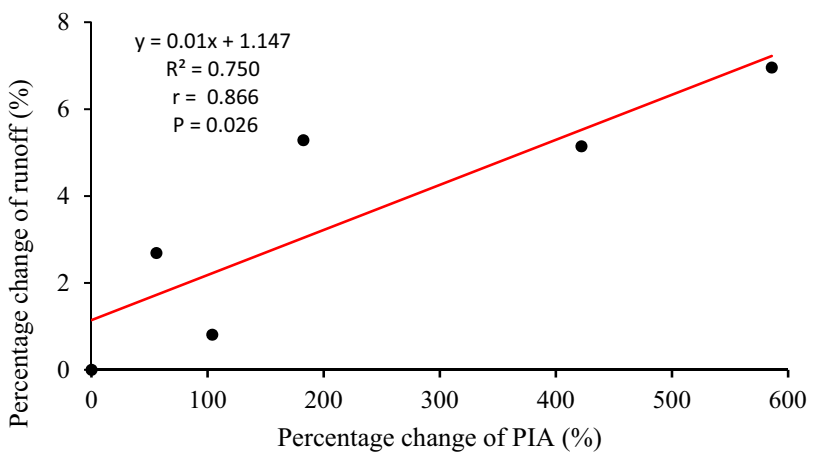

(b) Awash watershed

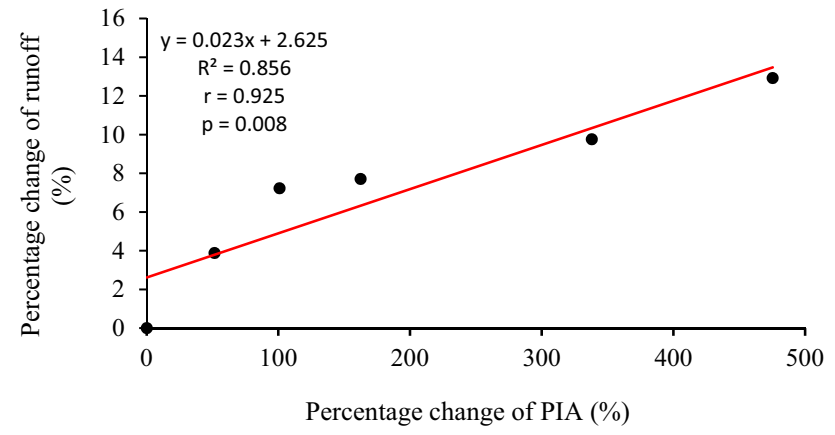

(c) Mermersa watershed

Fig. 6 Relationship between spatio-temporal changes of runoff depth and imperviousness in Adama city administration and its sub-watersheds from 1995 to 2019 with respect to the baseline year

Chen et al. [11] in which the deviation from a linear relationship between urban expansion and runoff variation is reported for some of the analyzed watersheds pertaining to northern China. The result of this study is referred to Adama city and its watersheds.

This study would increases understanding of the cumulative impact of urbanization in the hydrologic regime of the city and can be viewed as a springboard for all stakeholders. By limiting the extents of future impervious surfaces that can be converted from the remaining available land through new expansion, urban renewal and infill developments, the impacts of urbanization can be arguably managed to show sustainability of the city's development. It spotlights the potential of imperviousness ratio to be used as an alternate pragmatic planning tool for controlling the hydrologic influences attributable to urbanization and could be integrated to storm water management regulations.

\section{Conclusions}

The quantitative evidence obtained in this study revealed that Adama city has undergone an excessive LULC change over the last 24 years (1995-2019) with significant effects on hydrological attributes, which pressed an alarm for increasing flood hazards. During the study period, the urban built-up land area has been expanded by $22 \%$ annually. The overall impacts of these changes on hydrologic regime were increased runoff depth significantly. The magnitude of runoff in the city was increased by $9.5 \%$, while $12.9 \%$ and $6.9 \%$ increase are found in the case of Awash and Mermersa watersheds. Opposite effect of LULC changes on runoff is also obtained in the Awash watershed from 2000 to 2005. Moreover, the increases magnitude of runoff is linearly related to the spatio-temporal changes of imperviousness ratio, indicating an impervious surface-based land use regulation is required to guide future developments.

The findings in the study would provide valuable information related to the impacts of urbanization on runoff characteristics and can be helpful for decision makers and planners to scientifically develop sustainable land use plan in the study catchment. However, the results should be viewed as an initial step for understanding of the hydrologic influences attributable to urbanization and further studies are required in several fronts. The impacts of urbanization are assessed using the variations of accumulated runoff depth corresponding to variations in the volume of water yield. However, the impacts on other factors (e.g., Flow rate) and their combined effect on flooding needs further investigations. On the other, urbanization is undeniably an ongoing global trend, and decreasing the extent of imperviousness may not be always realistic. Hence, it is essential to investigate the possible ways to use the impervious surface in flood hazard management.

Acknowledgements This paper is a part of ongoing $\mathrm{PhD}$ dissertation by Dejene Tesema Bulti at Ethiopian Institute of Architecture, Building Construction and City Development (EiABC), Addis Ababa University, Ethiopia. We would like to thank the anonymous reviewers and the editor for their genuine comments and corrections which helps the paper to be in its present form.

Author contributions DTB has conceived of the study and made contributions in design, data collection and analysis, interpretation of 
the results and draft the manuscript. BGA supervised the study and reviewed the whole content. Both authors read and approved the manuscript.

\section{Compliance with ethical standards}

Conflict of interest The authors declare that they have no competing interests.

Consent for publication We have agreed to submit for SN Applied Science journal and approved the manuscript for submission.

\section{References}

1. Amani M, Brisco B, Afshar M, Mirmazloumi SM, Mahdavi S, Mirzadeh SMJ, Huang W, Granger J (2019) A generalized supervised classification scheme to produce provincial wetland inventory maps: an application of Google Earth Engine for big geo data processing. Big Earth Data 3(4):378-394. https://doi. org/10.1080/20964471.2019.1690404

2. Bajracharya AR, Rai RR, Rana S (2015) Effects of urbanization on storm water run-off: a case study of Kathmandu metropolitan city, Nepal. J Inst Eng 11(1):36-49. https://doi.org/10.3126/jie. v11i1.14694

3. Bansode A, Patil KA (2014) Estimation of runoff by using SCS curve number method and arc GIS. Int J Sci Eng Res 5(7):1283-1287

4. Billi P, Alemu YT, Ciampalini R (2015) Increased frequency of flash floods in Dire Dawa, Ethiopia: change in rainfall intensity or human impact? Nat Hazards 76:1373-1394. https://doi. org/10.1007/s11069-014-1554-0

5. Birhanu D, Kima H, Jang C, Parka S (2016) Flood risk and vulnerability of Addis Ababa City due to climate change and urbanization. In: 12th international conference on hydroinformatics, HIC 2016. Procedia engineering, vol 154, no 2016, pp 696-702

6. Bulti DT, Assefa T (2019) Analyzing ecological footprint of residential building construction in Adama City, Ethiopia. J Environ Syst Res 8:2. https://doi.org/10.1186/s40068-019-0130-8

7. Bulti DT, Sori ND (2017) Evaluating land-use plan using conformance-based approach in Adama city, Ethiopia. Spat Inf Res. https ://doi.org/10.1007/s41324-017-0125-3

8. Bulti DT, Mekonnen B, Bekele M (2017) Assessment of Adama city flood risk using multicriteria approach. Ethiop J Sci Sustain Dev EJSSD 4(1):6-23

9. Chattefuee S, Hadi AS (2006) Regression analysis by example, 4th edn. Wiley, Hoboken

10. Chen J, Theller L, Gitau MW, Engel BA, Harbor JM (2017) Urbanization impacts on surface runoff of the contiguous United States. J Environ Manag 187:470-481. https://doi.org/10.1016/j. jenvman.2016.11.017

11. Chen X, Tian C, Meng X, Xu Q, Cui G, Zhang Q, Xiang X (2015) Analyzing the effect of urbanization on flood characteristics at catchment levels. Int Assoc Hydrol Sci 370:33-38

12. Chen Y, Wang Q, Wang Y, Duan S, Xu M, Li Z (2016) A spectral signature shape-based algorithm for landsat image classification. ISPRS Int J Geo Inf 5(154):1-16. https://doi.org/10.3390/ ijgi5090154

13. Cherian B, Das DP, John L, Devadathan M, Malakeel GS (2017) A study on impact of urbanization on surface runoff in Muvattupuzha municipality. Int J Innov Res Sci Eng Technol 6(4):58145821. https://doi.org/10.15680/IJIRSET.2017.0604195
14. Congalton RG, Green K (2009) Assessing the accuracy of remotely sensed data: principles and practices, 2 nd edn. CRS Press, Baco Ratton

15. Demeke GG, Andualem TG (2018) Application of remote sensing for evaluation of land use change responses on hydrology of Muga watershed, Abbay River Basin, Ethiopia. J Earth Sci Clim Change. https://doi.org/10.4172/21577617.1000493

16. Deribew KT, Dalacho DW (2019) Land use and forest cover dynamics in the North-eastern Addis Ababa, central highlands of Ethiopia. J Environ Syst Res. https://doi.org/10.1186/s4006 8-019-0137-1

17. Dinka MO, Chaka DD (2019) Analysis of land use/land cover change in Adei watershed, Central Highlands of Ethiopia. J Water Land Dev 41(IV-VI):146-153. https://doi.org/10.2478/ jwld-2019-0038

18. Emilsson T, Ode Sang A (2017) Impacts of climate change on urban areas and nature-based solutions for adaptation. In: Kabisch $\mathrm{N}$ et al (eds) Nature-based solutions to climate change adaptation in urban areas, theory and practice of urban sustainability transitions. https://doi.org/10.1007/9783-319-56091-5_2

19. Erena SH, Worku H (2018) Flood risk analysis causes and landscape based mitigation strategies in Dire Dawa city, Ethiopia. Geoenviron Disasters. https://doi.org/10.1186/s4067 7-018-0110-8

20. Esa E, Assen M, Legass A (2018) Implications of land use/cover dynamics on soil erosion potential of agricultural watershed, northwestern highlands of Ethiopia. J Environ Syst Res. https:// doi.org/10.1186/s40068-018-0122-0

21. Fonji SF, Taff GN (2014) Using satellite data to monitor land-use land-cover change in North-eastern Latvia. SpringerPlus. https ://doi.org/10.1186/2193-1801-3-61

22. Foody GM (2002) Status of land cover classification accuracy assessment. Remote Sens Environ 80(2002):185-201. https:// doi.org/10.1016/s0034-4257(01)00295-4

23. Gashaw T, Tulu T, Argaw M, Worqlul AW (2017) Evaluation and prediction of land use/land cover changes in the Andassa watershed, Blue Nile Basin, Ethiopia. J Environ Syst Res. https:// doi.org/10.1186/s40068-017-0094-5

24. Gelman A (2012) P-values and statistical practice. Epidemiology 24(1):69-72

25. Getachew HE, Melesse AM (2012) The impact of land use change on the hydrology of the Angereb watershed, Ethiopia. Int J Water 1(4):1-7. https://doi.org/10.5772/56266

26. Getahun YS, Van Lanen HAJ (2015) Assessing the impacts of land use-cover change on hydrology of Melka Kuntrie Subbasin in Ethiopia, using a conceptual hydrological model. Hydrol Curr Res. https://doi.org/10.4172/21577587.1000210

27. Gunn R, Martin A, Engel B, Ahiablame L (2012) Development of two indices for determining hydrologic implications of land use changes in urban areas. Urban Water J 9(4):239-248. https://doi. org/10.1080/1573062X.2012.660957

28. Gutman G, Huang C, Chander G, Noojipady P, Masek JG (2013) Assessment of the NASA-USGS global landsurvey (GLS) datasets. Remote Sens Environ 134:249-265

29. Guzha AC, Rufino MC, Okoth S, Jacobs S, Nóbrega RLB (2018) Impacts of land use and land cover change on surface runoff, discharge and low flows: evidence from East Africa. J Hydrol Reg Stud 15:49-67. https://doi.org/10.1016/j.ejrh.2017.11.005

30. Hassen EE, Assen M (2017) Land use/cover dynamics and its drivers in Gelda catchment, Lake Tana watershed, Ethiopia. J Environ Syst Res. https://doi.org/10.1186/s40068-017-0081-x

31. Jacobson CR (2011) Identification and quantification of the hydrological impacts of imperviousness in urban catchments: a review. J Environ Manag 92:1438-1448. https://doi. org/10.1016/j.jenvman.2011.01.018 
32. Liu Y, Luo T, Liu Z, Kong X, Li J, Tan R (2015) A Comparative analysis of urban and rural construction land use change and driving forces: implications for urban-rural coordination development in Wuhan, Central China. Habitat Int 47:113-125

33. Lu D, Weng Q (2007) A survey of image classification methods and techniques for improving classification performance. Int J Remote Sens 28:823-870

34. Mejía Al, Moglen GE (2009) Spatial patterns of urban development from optimization of flood peaks and imperviousnessbased measures. J Hydrol Eng 14:416-424

35. Mekonnen DF, Duan Z, Rientjes T, Disse M (2018) Analysis of combined and isolated effects of land-use and land-cover changes and climate change on the upper Blue Nile River basin's stream flow. Hydrol Earth Syst Sci 22:6187-6207. https://doi. org/10.5194/hess-22-6187-2018

36. Mentens J, Raes D, Hermy M (2006) Green roofs as a tool for solving the rainwater runoff problem in the urbanized 21st century? Landsc Urban Plan 77:217-226. https://doi.org/10.1016/j.landu rbplan.2005.02.010

37. Pandey AC (2017) Geospatial technique for runoff estimation based on SCS-CN method in upper south koel river basin of Jharkhand (India). Int J Hydrol 1(7):213-220. https://doi. org/10.15406/ijh.2017.01.00037

38. Parece TE, Campbell JB (2013) Comparing urban impervious surface identification using landsat and high-resolution aerial photography. Remote Sens 5:4942-4960. https://doi.org/10.3390/ rs5104942

39. Phiri D, Morgenroth J (2017) Developments in landsat land cover classification methods: a review. Remote Sens. https:// doi.org/10.3390/rs9090967

40. Ramamurthy P, Bou-Zeid E (2014) Contribution of impervious surfaces to urban evaporation. Water Resour Res 50:2889-2902. https://doi.org/10.1002/2013WR013909

41. Rao GS, Giridhar MVSS, Mohan S, Sowmya P (2017) SCS-CN method and geomatics approach for fully distributed runoff modelling. Int J Comput Eng Res: IJCER 7(9):20-26

42. Rasul $A$, Balzter $H$, Ibrahim GRF, Hameed HM, Wheeler J, Adamu B, Ibrahim S, Najmaddin PM (2018) Applying built-up and baresoil indices from landsat 8 to cities in dry climates. Land. https ://doi.org/10.3390/land7030081

43. Rosenzweig BR, McPhillips L, Chang H, Cheng C, Welty C, Matsler M, Iwaniec D, Davidson Cl (2018) Pluvial flood risk and opportunities for resilience. WIREs Water. https://doi.org/10.1002/ wat2.1302

44. Saberifar R, Shokri H (2016) Analyzing the effects of urban development on flooding in the cities: case of Birjand city. Nat Environ Change 2(2):177-186

45. Sanyal J, Densmore AL, Carbonneau P (2014) Analyzing the effect of land-use/cover changes a sub-catchment levels on downstream flood peaks: a semi-distributed modelling approach with sparse data. CATENA 118:28-40. https://doi. org/10.1016/j.catena.2014.01.015
46. Seltman HJ (2018) Experimental design and analysis. http:// www.stat.cmu.edu/hseltman/309/Book/. Accessed 5 Sept 2018

47. Sertel E, Akay SS (2015) High resolution mapping of urban areas using SPOT-5 images and ancillary data. Int J Environ Geoinform 2(2):63-76

48. Shewangizaw D, Michael Y (2010) Assessing the effect of land use change on the hydraulic regime of lake Awassa. Nile Basin Water Sci Eng J 3(2):110-118

49. Sinha P, Verma NK, Ayele E (2016) Urban built-up area extraction and change detection of Adama municipal area using timeseries landsat images. Int J Adv Remote Sens GIS 5(8):18861895. https://doi.org/10.23953/cloud.ijarsg.67

50. Su W, Ye G, Yao S, Yang G (2014) Urban land pattern impacts on floods in a new district of China. Sustainability 6:6488-6508. https://doi.org/10.3390/su6106488

51. Subramanya K (2008) Engineering hydrology, 3rd edn. McGrawHill Education, Noida

52. Tabbutt V, Ambrogi M (2013) Estimates of current and future impervious area and forest lands vulnerable to urban conversion for watershed based land use planning Thurston county. United States, Environmental Protection Agency, Washington

53. Tilahun A, Teferie B (2015) Accuracy assessment of land use land cover classification using Google Earth. Am J Environ Prot 4(4):193-198. https://doi.org/10.11648/j.ajep.20150404.14

54. UN (2018) Handbook of statistics. In: United Nations conference on trade and development (UNCTAD). United Nations, New York

55. van Roon M (2011) Low impact urban design and development: catchment-based structure planning to optimise ecological outcomes. Urban Water J 8(5):293-308. https://doi. org/10.1080/1573062X.2011.598172

56. Weng Q (2010) Remote sensing and GIS integration: theories, methods, and applications. McGraw-Hill, New York

57. Yohannes AW, Cotter M, Kelboro G, Dessalegn W (2018) Land use and land cover changes and their effects on the landscape of Abaya-Chamo Basin, Southern Ethiopia. Land 7(2):1-17. https ://doi.org/10.3390/land7010002

58. Yu H, Zhao Y, Fu Y, Li L (2018) spatiotemporal variance assessment of urban rainstorm waterlogging affected by impervious surface expansion: a case study of Guangzhou, China. Sustainability. https://doi.org/10.3390/su10103761

59. Zhang H, Wang T, Zhang Y, Dai Y, Jia J, Yu C, Li G, Lin Y, Lin H, Cao $Y$ (2018) Quantifying short-term urban land cover change with time-series landsat data: a comparison of four different cities. Sensors 18(4319):1-23. https://doi.org/10.3390/s18124319

Publisher's Note Springer Nature remains neutral with regard to jurisdictional claims in published maps and institutional affiliations. 